\title{
Optimization of D-lactic acid production using unutilized biomass as substrates by multiple parallel fermentation
}

\author{
Elya Mufidah $^{1} \cdot$ Mamoru Wakayama ${ }^{1}$
}

Received: 4 April 2016/Accepted: 16 August 2016/Published online: 31 August 2016

(c) The Author(s) 2016. This article is published with open access at Springerlink.com

\begin{abstract}
This study investigated the optimization of Dlactic acid production from unutilized biomass, specifically banana peel and corncob by multiple parallel fermentation (MPF) with Leuconostoc mesenteroides and Aspergillus awamori. The factors involved in MPF that were assessed in this study comprised banana peel and corncob, $\mathrm{KH}_{2} \mathrm{PO}_{4}$, Tween $80, \mathrm{MgSO}_{4} \cdot 7 \mathrm{H}_{2} \mathrm{O}, \mathrm{NaCl}$, yeast extract, and diammonium hydrogen citrate to identify the optimal concentration for D-lactic acid production. Optimization of these component factors was performed using the Taguchi method with an L8 orthogonal array. The optimal concentrations for the effectiveness of MPF using biomass substrates were as follows: (1) banana peel, D-lactic acid production was $31.8 \mathrm{~g} / \mathrm{L}$ in medium containing $15 \%$ carbon source, $0.5 \% \mathrm{KH}_{2} \mathrm{PO}_{4}, 0.1 \%$ Tween $80,0.05 \%$ $\mathrm{MgSO}_{4} \cdot 7 \mathrm{H}_{2} \mathrm{O}, 0.05 \% \mathrm{NaCl}, 1.5 \%$ yeast extract, and $0.2 \%$ diammonium hydrogen citrate. (2) corncob, D-lactic acid production was $38.3 \mathrm{~g} / \mathrm{L}$ in medium containing $15 \%$ of a carbon source, $0.5 \% \mathrm{KH}_{2} \mathrm{PO}_{4}, 0.1 \%$ Tween 80 , $0.05 \% \mathrm{MgSO}_{4} \cdot 7 \mathrm{H}_{2} \mathrm{O}, 0.1 \% \mathrm{NaCl}, 1.0 \%$ yeast extract, and $0.4 \%$ diammonium hydrogen citrate. Thus, both banana peel and corncob are unutilized potential resources for D-lactic acid production. These results indicate that MPF using L. mesenteroides and A. awamori could constitute part of a potential industrial application of the currently unutilized banana peel and corncob biomass for Dlactic acid production.
\end{abstract}

Mamoru Wakayama

wakayama@sk.ritsumei.ac.jp

1 Department of Biotechnology, Graduate School of Life Sciences, Ritsumeikan University, 1-1-1 Nojihigashi, Kusatsu, Shiga 525-8577, Japan
Keywords D-Lactic acid - Leuconostoc mesenteroides . Banana peel · Corncob - Multiple parallel fermentation · Optimization

\section{Introduction}

Lactic acid plays significant roles in several biochemical processes and exists in nature as two optical isomers, Dand L-lactic acid (Benninga 1990). Lactic acid is found primarily in sour milk products, such as koumiss, yogurt, kefir, and some cottage cheeses. The casein in fermented milk is coagulated (curdled) by lactic acid. Lactic acid is also responsible for the sour flavor of sourdough breads (Carminati et al. 2010). In the chemical industry, both Dand L-lactic acid have many uses as food chemicals, preservatives, oxygenated chemicals, plant growth regulators, raw materials for biodegradable polymers and environmentally friendly solvents (Datta and Tsai 1997; Richard and Nwabunma 2010; Wang et al. 2003).

Various microorganisms produce sufficient amount of lactic acid using various sugars, such as glucose, sucrose, and lactose (Richard and Nwabunma 2010). For example, glucose can be easily exploited to produce $25.4 \mathrm{~g} / \mathrm{L}$ of Llactic acid in LB medium after $48 \mathrm{~h}$ through simple fermentation using Bacillus licheniformis (Wang et al. 2011). It was also reported that Leuconostoc mesenteroides produced $66.11 \mathrm{~g} / \mathrm{L}$ of D-lactic acid using an optimal combination of yeast auto-lysate and sugarcane juice containing sucrose (Coelho et al. 2011) and recombinant E. coli JH15 produced $88 \mathrm{~g} / \mathrm{L}$ of D-lactic acid from a mixed glucose and xylose in $36 \mathrm{~h}$ fermentation (Lu et al. 2016). Similarly, Rhizopus oryzae ATCC 52311 produced $83 \mathrm{~g} / \mathrm{L}$ of L-lactic acid from glucose in $32 \mathrm{~h}$ of fermentation (Zhou et al. 1999). 
Agricultural residues such as banana peel and corncob are potential sources of renewable energy (Rehman et al. 2014; Jeevan et al. 2011). These unutilized raw biomaterials have also received attention as potential substrates for lactic acid fermentation. When unutilized biomass is used as a carbon source, it must first be saccharified because most lactic acid bacteria cannot utilize it directly (Luo et al. 1997; Ghowdaman and Ponnusami 2015). In addition, pretreatment such as alkali or acid treatment of unutilized raw biomaterials is often required before saccharification. Pretreatment methods for unutilized raw biomaterials have an influence on saccharification efficiency and will indirectly affect for lactic acid production (Sasaki et al. 2012). There have been reports on lactic acid production using unutilized raw biomaterials. Using corncob as a substrate, $R$. oryzae NRRL-395 produced $299.4 \mathrm{~g}$ L-lactic acid per $\mathrm{kg}$ dry matter in $48 \mathrm{~h}$ of fermentation at $30^{\circ} \mathrm{C}$ (Ruengruglikit and Hang 2003), while simultaneous saccharification and fermentation of Acremonium cellulose and Rhizopus sp. produced $24.0 \mathrm{~g} / \mathrm{L}$ L-lactic acid in $48 \mathrm{~h}$ (Miura et al. 2004). Additionally, Lactobacillus delbrueckii IFO 3202 produced $28 \mathrm{~kg} \mathrm{~m}^{-3}$ D-lactic acid using 100 $\mathrm{kg} \mathrm{m}^{-3}$ rice bran as a substrate in $36 \mathrm{~h}$ at $37^{\circ} \mathrm{C}$ by simultaneous saccharification and fermentation (Tanaka et al. 2005) and L. delbrueckii produced $16.5 \mathrm{~g} / \mathrm{L}$ of Dlactic acid using sugarcane bagasse and a steam explosion pretreatment (Sasaki et al. 2012).

As described above, D-lactic acid production by $L$. mesenteroides using sugarcane juice has been reported (Coelho et al. 2011). Although sugarcane juice is easily exploited as a base material for D-lactic acid fermentation without a time- and labor-consuming pretreatment, sugarcane is also valuable, primarily as sweetener in the food industry. Thus, production of D-lactic acid from fermentation of otherwise unutilized raw biomaterials, such as banana peel, corncob, rice bran, and sugarcane bagasse, would be advantageous. There have been no reports on D-lactic acid production from banana peel or corncob by $L$. mesenteroides. In this case, a pretreatment with safe chemical reagents on unutilized biomass substrate, banana peel and corncob should be taken into account. Consequently, it leads to an efficient hydrolysis of biomass substrates by fungi, which combines with Dlactic acid fermentation process using L. mesenteroides. The present study investigated optimization of D-lactic acid production using banana peel and corncob as fermentation substrates for multiple parallel fermentation via Leuconostoc mesenteroides and Aspergillus awamori, a koji mold used in Japanese spirit brewing.

\section{Materials and methods}

\section{Microorganisms}

The lactic acid bacteria used in this study were Leuconostoc mesenteroides subsp. mesenteroides (NBRC 3426, NBRC 3832, and NBRC 12060), and Leuconostoc mesenteroides subsp. dextranicum (NBRC 3349, NBRC 100495). The following fungi were evaluated for their capacity to aid in degradation of biomass substrates, Aspergillus niger NBRC 4414, Aspergillus awamori NBRC 4388, Rhizopus oryzae NBRC 4706, Rhizopus microspores NBRC 3200, Aspergillus oryzae NBRC 100959, and Aspergillus sojae NBRC 33802.

\section{Media and cultivation}

\section{Medium condition for fungi}

For fungi cultivation, the growth liquid medium was $1 \%$ of a carbon source (banana peel or corncob), $0.25 \%$ $\mathrm{KH}_{2} \mathrm{PO}_{4}, 0.1 \%$ yeast extract, $0.035 \% \quad \mathrm{MgSO}_{4} \cdot 7 \mathrm{H}_{2} \mathrm{O}$, $0.035 \%$ urea, $0.1 \%$ Tween 80, $0.005 \% \mathrm{FeSO}_{4} \cdot \mathrm{H}_{2} \mathrm{O}$, $0.001 \% \mathrm{MnSO}_{4} \cdot \mathrm{H}_{2} \mathrm{O}$, and $0.1 \% \mathrm{NaCl}$. The initial $\mathrm{pH}$ was adjusted to 5.6. A total of $5 \mathrm{~mL}$ of the inoculum with $3 \%$ of calcium carbonate was transferred to $100-\mathrm{mL}$ Erlenmeyer flasks containing $50 \mathrm{~mL}$ of medium. Cultivation was carried out in flask cultures at $30{ }^{\circ} \mathrm{C}$ on a rotary shaker at $120 \mathrm{rpm}$.

\section{Medium condition for lactic acid bacteria}

MRS medium was used for lactic acid bacteria (Coelho et al. 2011). The liquid MRS composition was as follows: $1.5 \%$ poly peptone, $0.5 \%$ yeast extract, $1.0 \%$ beef extract, $2.0 \%$ glucose, $0.7 \%$ sodium acetate, $0.3 \%$ diammonium hydrogen citrate, $0.4 \%$ di-potassium hydrogen phosphate, $0.02 \% \mathrm{MgSO}_{4} \cdot 7 \mathrm{H}_{2} \mathrm{O}$, and $0.004 \%$ $\mathrm{MnSO}_{4} \cdot 4 \mathrm{H}_{2} \mathrm{O}$. The initial $\mathrm{pH}$ was adjusted to 6.3 . A total of $10 \mathrm{~mL}$ of the inoculum with $3 \%$ of calcium carbonate was transferred to a 200-mL Erlenmeyer flask containing $100 \mathrm{~mL}$ of the medium. Cultivation was carried out in flask cultures at $30{ }^{\circ} \mathrm{C}$ on a rotary shaker at $100 \mathrm{rpm}$.

\section{Pretreatment of fermentation substrates}

Banana peel (Musa acuminata balbisiana Colla) was collected from household waste, and corncob (Zea mays) was supplied by a small cornstarch factory in Bali, Indonesia. Before banana peel was utilized, it was cut into small 5- to $8-\mathrm{cm}$ pieces using a stainless steel knife. The banana peel 
was then soaked in $1 \%$ sodium thiosulfate solution for $5 \mathrm{~h}$ at $30{ }^{\circ} \mathrm{C}$ to inhibit the oxidation processes, thus preventing browning to get a better texture for use of the banana peel in lactic acid production (unpublished data). Milled corncob was soaked in a $0.5 \%$ sodium hypochlorite solution for delignification for approximately $6 \mathrm{~h}$ at $30{ }^{\circ} \mathrm{C}$, followed by a drying process in a hot air oven (Ghowdaman and Ponnusami 2015). The small dried pieces of both banana peel and corncob were collected by sieving with a $<1-\mathrm{mm}$ mesh net.

\section{Multiple parallel fermentation}

Multiple parallel fermentation (MPF) is the combination of biomass substrate degradation by fungi with lactic acid fermentation by $L$. mesenteroides. After cultivation of fungi for $36 \mathrm{~h}$, L. mesenteroides NBRC 3832 was inoculated to the culture medium of fungi for D-lactic acid production by MPF. The liquid medium for multiple parallel fermentation included $3 \%$ carbon source (banana peel or corncob), $0.25 \% \mathrm{KH}_{2} \mathrm{PO}_{4}, 0.5 \%$ yeast extract, $0.05 \%$ $\mathrm{MgSO}_{4} \cdot 7 \mathrm{H}_{2} \mathrm{O}, 0.05 \%$ urea, $0.1 \%$ Tween $80,0.005 \%$ $\mathrm{FeSO}_{4} \cdot \mathrm{H}_{2} \mathrm{O}, 0.001 \% \mathrm{MnSO}_{4} \cdot \mathrm{H}_{2} \mathrm{O}, \quad 0.2 \%$ diammonium hydrogen citrate and $0.1 \% \mathrm{NaCl}$. The initial $\mathrm{pH}$ was adjusted to 5.6. A total of $10 \mathrm{~mL}$ of the inoculum with $3 \%$ calcium carbonate was transferred to a 300-mL Erlenmeyer flask containing $200 \mathrm{~mL}$ of medium. MPF was performed at $30^{\circ} \mathrm{C}$ in an incubator with gentle shaking at $120 \mathrm{rpm}$ during hydrolysis by fungi and at $100 \mathrm{rpm}$ after hydrolysis to allow the media and inoculum to be mixed homogeneously.

\section{Analytical methods}

Reducing sugar was measured using the Somogyi-Nelson method (Somogyi 1952). The protein concentration was determined using either the Lowry method with bovine serum albumin as the standard (Lowry et al. 1951) or by monitoring the optical density at $280 \mathrm{~nm}$. The activities of xylanase, pectinase, amylase, $\beta$-glucosidase, and endoglucanases in culture mediums with banana peel and corncob as biomass substrates were determined as follows. Crude enzyme preparation $(100 \mu \mathrm{L})$ was incubated with the relevant substrate $(1 \% \mathrm{w} / \mathrm{v})$ (beech wood xylan for xylanase, citrus pectin for pectinase, starch for amylase, salicin for $\beta$ glucosidase, and carboxymethyl cellulose for endoglucanase) in $50 \mathrm{mM}$ acetate buffer at $\mathrm{pH} 5.0(1.0 \mathrm{~mL}$ of reaction mixture). The amount of reducing sugars was determined using the Somogyi-Nelson method against the standard curves of xylose, galacturonic acid, and glucose. The amount of enzyme that released $1 \mu \mathrm{mol}$ of reducing sugar per minute under standard assay conditions was defined as one international unit (U) of enzyme. D-Lactic acid was measured according to the instructions from Boehringer Mannheim/R-Biopharm with minor modification. The reaction solution consisted of $222 \mathrm{mM}$ glycylglycine buffer ( $\mathrm{pH}$ 10.0), $100 \mathrm{mM}$ L-glutamic acid, $52.8 \mathrm{mM} \mathrm{NAD}^{+}, 13.66 \mathrm{U}$ of glutamate-pyruvate transaminase, and $6.79 \mathrm{U}$ of D-lactate dehydrogenase. The absorbance increase of NADH at $340 \mathrm{~nm}$ was determined. Measurement of L-lactic acid was also carried out using $43.48 \mathrm{U}$ of L-lactate dehydrogenase instead of D-lactate dehydrogenase.

\section{Experimental design}

The optimal MPF conditions for production of D-lactic acid were determined using the method from Taguchi, in which variables or factors were arranged in an L8 orthogonal array (OA). All calculations and analyses were performed using Qualitek-4 software for automatic design and analysis of Taguchi experiments. The factor levels and L8 OA layout are presented in Table 1a and $\mathrm{b}$. The signal-to-noise ratio $(\mathrm{S} / \mathrm{N})$ shows the extent of all factor effects. This approach introduces the $\mathrm{S} / \mathrm{N}$ ratio to examine the influence of the noise factor on variation. For the $\mathrm{S} / \mathrm{N}$ ratio, characteristic types defined by the larger the better means that the highest value is the best quality (Ravella et al. 2008).

\section{Results and discussion}

\section{Screening of microorganisms}

The liquid fermentation abilities of the microorganisms used in this study were assessed to determine the bacteria that produced the highest amounts of D-lactic acid. Among the lactic acid bacteria examined, L. mesenteroides NBRC 3832 produced the highest amounts of D-lactic acid $(6.74 \mathrm{~g} /$ L) by simple fermentation using $2 \%$ glucose in MRS medium, with sugar consumption of approximately $89.1 \%$ during $96 \mathrm{~h}$ (unpublished data). Next, to select the fungus that is most suitable for MPF with L. mesenteroides NBRC 3832, fungal contribution to D-lactic acid production via the saccharification of biomass substrates was evaluated. $A$. niger NBRC 4414, A. awamori NBRC 4388, R. oryzae NBRC 4706, $R$. microspores NBRC 3200, A. oryzae NBRC 100959 , and $A$. sojae NBRC33802 were tested in a preliminary experiment. Of these, using banana peel and corncob, A. awamori NBRC 4388 showed the highest Dlactic acid production by MPF with $L$. mesenteroides NBRC 3832. In this case, A. awamori NBRC 4388 was cultured in the liquid medium for MPF containing $3 \%$ of carbon sources, banana peel and corncob. After hydrolysis for 36 h, A. awamori NBRC 4388 produced reducing sugar from banana peel and corncob, 2.41 and $1.01 \mathrm{~g} / \mathrm{L}$ as 
Table 1 Condition of factors and its level (a) and experimental design using $\mathrm{L}_{8}\left(2^{7}\right)$ orthogonal array (b) of Taguchi method for multiple parallel fermentation using banana peel and corncob as carbon sources

\begin{tabular}{|c|c|c|c|c|c|c|c|c|c|}
\hline \multicolumn{7}{|c|}{ (a) Factors } & \multicolumn{2}{|c|}{ Level 1} & Level 2 \\
\hline \multicolumn{7}{|c|}{ X1. Banana peel (a), corncob (b); (\%) } & \multicolumn{2}{|c|}{10} & 15 \\
\hline \multicolumn{7}{|c|}{$\mathrm{X} 2 . \mathrm{KH}_{2} \mathrm{PO}_{4}(\%)$} & \multicolumn{2}{|c|}{0.5} & 1 \\
\hline \multicolumn{7}{|c|}{$\mathrm{X} 3 . \mathrm{NaCl}(\%)$} & \multicolumn{2}{|c|}{0.05} & 0.1 \\
\hline \multicolumn{7}{|c|}{ X4. Tween $80(\%)$} & \multicolumn{2}{|c|}{0.05} & 0.1 \\
\hline \multicolumn{7}{|c|}{ X5. Yeast extract (\%) } & \multicolumn{2}{|c|}{1} & 1.5 \\
\hline \multicolumn{7}{|c|}{ X6. $\mathrm{MgSO}_{4} \cdot 7 \mathrm{H}_{2} \mathrm{O}(\%)$} & \multicolumn{2}{|c|}{0.05} & 0.1 \\
\hline \multicolumn{7}{|c|}{ X7. Diammonium hydrogen citrate (\%) } & \multicolumn{2}{|c|}{0.2} & 0.1 \\
\hline \multirow[t]{2}{*}{ (b) Run } & \multicolumn{7}{|c|}{ Factors } & \multirow[t]{2}{*}{ SNR of $\mathrm{LTB}^{\mathrm{a}}$} & \multirow[t]{2}{*}{ SNR of $\mathrm{LTB}^{\mathrm{b}}$} \\
\hline & $\mathrm{X} 1$ & $\mathrm{X} 2$ & $\mathrm{X} 3$ & $\mathrm{X} 4$ & X5 & X6 & $\mathrm{X} 7$ & & \\
\hline 1 & 1 & 1 & 1 & 1 & 1 & 1 & 1 & $22.812 \pm 0.003$ & $25.713 \pm 0.021$ \\
\hline 2 & 1 & 1 & 1 & 2 & 2 & 2 & 2 & $22.088 \pm 0.023$ & $25.555 \pm 0.004$ \\
\hline 3 & 1 & 2 & 2 & 1 & 1 & 2 & 2 & $19.647 \pm 0.007$ & $25.342 \pm 0.004$ \\
\hline 4 & 1 & 2 & 2 & 2 & 2 & 1 & 1 & $22.524 \pm 0.011$ & $25.660 \pm 0.022$ \\
\hline 5 & 2 & 1 & 2 & 1 & 2 & 1 & 2 & $29.530 \pm 0.013$ & $29.115 \pm 0.032$ \\
\hline 6 & 2 & 1 & 2 & 2 & 1 & 2 & 1 & $29.011 \pm 0.022$ & $29.327 \pm 0.041$ \\
\hline 7 & 2 & 2 & 1 & 1 & 2 & 2 & 1 & $28.708 \pm 0.033$ & $25.889 \pm 0.007$ \\
\hline 8 & 2 & 2 & 1 & 2 & 1 & 1 & 2 & $29.230 \pm 0.014$ & $31.233 \pm 0.004$ \\
\hline
\end{tabular}

The number (1 and 2) below each factor $(\mathrm{X} 1-\mathrm{X} 7)$ indicates the level of each factor described in Table $1 \mathrm{~b}$

The values of signal-to-noise ratio ( $\mathrm{S} / \mathrm{N}$ ratio) represent the mean $\pm \mathrm{SD}(n=3)$

In signal-to-noise ratio, characteristic types of LTB (larger the better) means the highest value is the best of quality (Ravella et al. 2008)

The factors and their values were determined based on triplicate experiments $(n=3)$

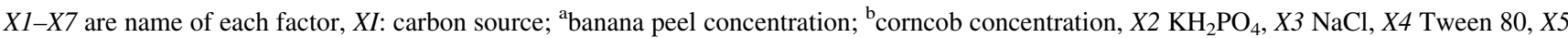
yeast extract, $X 6 \mathrm{MgSO}_{4} \cdot 7 \mathrm{H}_{2} \mathrm{O}, X 7$ diammonium hydrogen citrate

glucose equivalent, respectively. Successively, lactic acid fermentation by MPF with A. awamori NBRC 4388 and $L$. mesenteroides NBRC 3832 was performed for $48 \mathrm{~h}$. This MPF using banana peel and corncob showed the highest Dlactic acid production, 0.88 and $0.31 \mathrm{~g} / \mathrm{L}$, respectively. A. awamori NBRC 4388 was thus used as the fungus of choice for MPF in the remainder of the study. After a $36 \mathrm{~h}$ incubation of A. awamori with banana peel and corncob biomass substrates, thin-layer chromatography (TLC) revealed that glucose and xylose were detectable as visible spots (data not shown). However, as the method used crude products, the spots detected by the TLC analysis were unclear and also appeared as other scattered spots. Based on these results, MPF was conducted by incubating $L$. mesenteroides with the A. awamori culture for $36 \mathrm{~h}$.

\section{Effect of a biomass substrate pretreatment on D-lactic acid production}

In a preliminary experiment, the effect of a biomass substrate pretreatment on D-lactic acid production was examined. With banana peel and corncob biomass substrates, Dlactic acid production was higher with pretreatment than

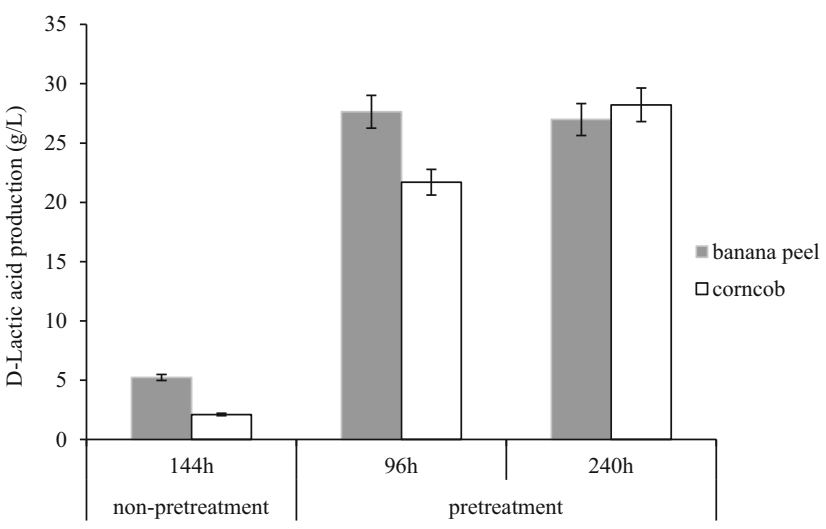

Fig. 1 Effect of pretreatment of banana peel and corncob biomass substrates on D-lactic acid production. The results are expressed as Dlactic acid production $(\mathrm{g} / \mathrm{L})$ in multiple parallel fermentation using $A$. awamori NBRC 4388. The growth medium for cultivation is described in the text. After 36-h hydrolysis by A. awamori NBRC 4388 , followed by inoculation of $L$. mesenteroides NBRC 3832 to Dlactic acid production by MPF, then cultivation was carried out with rotary shakers at $30{ }^{\circ} \mathrm{C}$. The values represent the mean $\pm \mathrm{SD}(n=3)$

without pretreatment (Fig. 1). This result confirms that pretreatment for MPF is strongly recommended when using biomass substrate. 


\section{D-Lactic acid production from biomass substrates by MPF}

The carbon source noticeably affected MPF production of Dlactic acid. The effect, variance, and contribution of each selected factor were assessed by analysis of variance (ANOVA). Variables with a confidence level greater than $95 \%$ were considered to have a significant influence over lactic acid production. The concentration of banana peel and corncob biomass substrates was of paramount importance for D-lactic acid production by MPF. The contributions of banana peel and corncob biomass substrates to D-lactic acid production were 97.20 and $56.06 \%$, respectively, and were supported by addition of $\mathrm{KH}_{2} \mathrm{PO}_{4}, \mathrm{NaCl}$, Tween 80 , yeast extract, $\mathrm{MgSO}_{4}$, and diammonium hydrogen citrate (Table 2). The results indicate that the type and concentration of the carbon source are the most important factors in determining optimal D-lactic acid production, and that each factor contributes differently to the production. Diammonium hydrogen citrate in MPF using banana peel and $\mathrm{NaCl}$ in MPF using corncob showed minor contributions to Dlactic acid production when these different sources of carbon were used as a substrate ( 0.043 and $0.044 \%$, respectively).

\section{Using banana peel as a substrate}

Optimization of MPF revealed that production of D-lactic acid from banana peel substrate $(31.8 \mathrm{~g} / \mathrm{L}$, productivity;
$0.331 \mathrm{~g} / \mathrm{L} / \mathrm{h}$ ) was most efficient with $15 \%$ banana peel, $0.5 \% \mathrm{KH}_{2} \mathrm{PO}_{4}, 0.1 \%$ Tween $80,0.05 \% \mathrm{MgSO}_{4} \cdot 7 \mathrm{H}_{2} \mathrm{O}$, $0.05 \% \mathrm{NaCl}, 1.5 \%$ yeast extract, and $0.2 \%$ diammonium hydrogen citrate using a rotary shaker after hydrolysis of the substrates by A. awamori for $36 \mathrm{~h}$ (Table 3a).

\section{Using corncob as a substrate}

Optimization of MPF revealed that production of D-lactic acid from corncob substrate $(38.3 \mathrm{~g} / \mathrm{L}$, productivity; $0.159 \mathrm{~g} / \mathrm{L} / \mathrm{h}$ ) was most efficient by MPF with $15 \%$ corncob, $0.5 \% \mathrm{KH}_{2} \mathrm{PO}_{4}, 0.1 \%$ Tween $80,0.05 \% \mathrm{MgSO}_{4-}$ $7 \mathrm{H}_{2} \mathrm{O}, 0.1 \% \mathrm{NaCl}, \quad 1.0 \%$ yeast extract, and $0.4 \%$ diammonium hydrogen citrate using a rotary shaker after hydrolysis of substrates by A. awamori for $36 \mathrm{~h}$ (Table $3 \mathrm{~b}$ ).

The optimum fermentation time for high D-lactic acid production using banana peel and corncob were 96 and $240 \mathrm{~h}$, respectively. D-Lactic acid production using banana peel required a much shorter fermentation time than that using corncob. L-Lactic acid was generally undetected (below $0.016 \%$ of D-lactic acid); thus, the optical purity of D-lactic acid in MPFs using banana peel and corncob were calculated to be 99.99 and $99.98 \%$, respectively. D-Lactic acid production by MPF using banana peel is more efficient than using corncob. Specifically, D-lactic acid production by MPF using corncob (38.3 g/L productivity $0.159 \mathrm{~g} / \mathrm{L} / \mathrm{h})$ exhibited higher yield than L-lactic acid by simultaneous saccharification fermentation of Acremonium cellulose and

Table 2 Analysis of variance (ANOVA) for D-lactic acid production using banana peel (a) and corncob (b)

\begin{tabular}{|c|c|c|c|c|c|c|}
\hline (a) $\mathrm{Col} /$ factors & DOF (f) & Sum of sqrs $(\mathrm{S})$ & Variance $(\mathrm{V})$ & F-ratio $(\mathrm{F})$ & Pure sum (S') & Percent P $(\%)$ \\
\hline Banana peel & 1 & 1575.693 & 1575.693 & 24428.458 & 1575.629 & 97.197 \\
\hline $\mathrm{KH}_{2} \mathrm{PO}_{4}$ & 1 & 11.599 & 11.599 & 179.838 & 11.535 & 0.711 \\
\hline $\mathrm{NaCl}$ & 1 & 0.949 & 0.949 & 14.723 & 0.885 & 0.054 \\
\hline Tween 80 & 1 & 2.577 & 2.577 & 39.965 & 2.513 & 0.155 \\
\hline Yeast extract & 1 & 2.775 & 2.775 & 43.03 & 2.711 & 0.167 \\
\hline $\mathrm{MgSO}_{4} \cdot 7 \mathrm{H}_{2} \mathrm{O}$ & 1 & 25.662 & 25.662 & 397.85 & 25.597 & 1.579 \\
\hline Diammonium hydrogen citrate & 1 & 0.765 & 0.765 & 11.868 & 0.701 & 0.043 \\
\hline Error & 16 & 1.031 & 0.064 & & & 0.094 \\
\hline Total & 23 & 1621.056 & & & & 100.00 \\
\hline (b) $\mathrm{Col} /$ factors & $\mathrm{DOF}(\mathrm{f})$ & Sum of sqrs (S) & Variance $(\mathrm{V})$ & F-ratio $(F)$ & Pure sum (S') & Percent $\mathrm{P}(\%)$ \\
\hline Corncob & 1 & 542.202 & 542.202 & 20823.353 & 542.176 & 56.060 \\
\hline $\mathrm{KH}_{2} \mathrm{PO}_{4}$ & 1 & 1.897 & 1.897 & 72.854 & 1.87 & 0.193 \\
\hline $\mathrm{NaCl}$ & 1 & 0.455 & 0.455 & 17.499 & 0.429 & 0.044 \\
\hline Tween 80 & 1 & 118.691 & 118.691 & 4558.353 & 118.665 & 12.269 \\
\hline Yeast extract & 1 & 109.731 & 109.731 & 4214.256 & 109.705 & 11.343 \\
\hline $\mathrm{MgSO}_{4} \cdot 7 \mathrm{H}_{2} \mathrm{O}$ & 1 & 109.32 & 109.32 & 4198.459 & 109.294 & 11.300 \\
\hline Diammonium hydrogen citrate & 1 & 84.419 & 84.419 & 3242.148 & 84.393 & 8.726 \\
\hline Error & 16 & 0.416 & 0.026 & & & 0.065 \\
\hline Total & 23 & 967.135 & & & & 100.00 \\
\hline
\end{tabular}


Table 3 Optimal condition and performance in validation of D-lactic acid production using banana peel (a) and corncob (b)

\begin{tabular}{|c|c|c|c|}
\hline (a) Factors $(\%)$ & Level description & Level & Contribution $(\mathrm{g} / \mathrm{L})$ \\
\hline Banana peel & 15 & 2 & 8.102 \\
\hline $\mathrm{KH}_{2} \mathrm{PO}_{4}$ & 0.5 & 1 & 0.695 \\
\hline $\mathrm{NaCl}$ & 0.05 & 1 & 0.198 \\
\hline Tween 80 & 0.1 & 2 & 0.327 \\
\hline Yeast extract & 1.5 & 2 & 0.340 \\
\hline $\mathrm{MgSO}_{4} \cdot 7 \mathrm{H}_{2} \mathrm{O}$ & 0.05 & 1 & 1.034 \\
\hline Diammonium hydrogen citrate & 0.2 & 1 & 0.178 \\
\hline Total contribution from all factors & & & 10.870 \\
\hline Current grand average of performance & & & 20.490 \\
\hline Expected result at optimum condition & & & 31.364 \\
\hline Validation result & & & 31.840 \\
\hline (b) Factors $(\%)$ & Level description & Level & Contribution $(\mathrm{g} / \mathrm{L})$ \\
\hline Corncob & 15 & 2 & 4.753 \\
\hline $\mathrm{KH}_{2} \mathrm{PO}_{4}$ & 0.5 & 1 & 0.281 \\
\hline $\mathrm{NaCl}$ & 0.1 & 2 & 0.137 \\
\hline Tween 80 & 0.1 & 2 & 2.223 \\
\hline Yeast extract & 1 & 1 & 2.138 \\
\hline $\mathrm{MgSO}_{4} \cdot 7 \mathrm{H}_{2} \mathrm{O}$ & 0.05 & 1 & 2.134 \\
\hline Diammonium hydrogen citrate & 0.4 & 2 & 1.875 \\
\hline Total contribution from all factors & & & 13.541 \\
\hline Current grand average of performance & & & 23.739 \\
\hline Expected result at optimum condition & & & 37.280 \\
\hline Validation result & & & 38.260 \\
\hline
\end{tabular}

All calculations and analysis were performed using Qualitek-4 software for automatic design

Rhizopus sp. using corncob $(24.0 \mathrm{~g} / \mathrm{L}$ productivity $0.170 \mathrm{~g} /$ $\mathrm{L} / \mathrm{h}$ ) (Miura et al. 2004). Thus, utilization of a biomass substrate as a carbon source has great potential for D-lactic acid production.

In MPF, carbon sources that $L$. mesenteroides can utilize for D-lactic acid fermentation are prepared by the enzymes produced by A. awamori and the productivity of D-lactic acid by $L$. mesenteroides is thought to be affected by the enzyme activities of A. awamori (data not shown). In this study, during hydrolytic processing when banana peel was used as the carbon source, $\beta$-glucosidase $(6.28 \mathrm{U} / \mathrm{mL})$ showed the highest enzymatic activity at $36 \mathrm{~h}$, followed by endoglucanase $(3.22 \mathrm{U} / \mathrm{mL})$, amylase $(2.34 \mathrm{U} / \mathrm{mL})$, xylanase $(0.31 \mathrm{U} / \mathrm{mL})$, and pectinase $(0.22 \mathrm{U} / \mathrm{mL})$. $\beta$-Glucosidase $(2.11 \mathrm{U} / \mathrm{mL})$ and endoglucanase $(1.01 \mathrm{U} / \mathrm{mL})$ activities decreased on the second day after inoculation with $L$. mesenteroides, whereas amylase $(5.23 \mathrm{U} / \mathrm{mL})$ and xylanase $(2.01 \mathrm{U} / \mathrm{mL})$ activities increased until the second day after inoculation of $L$. mesenteroides (data not shown). When corncob was used as the carbon source, $\beta$-glucosidase showed the highest enzymatic activity $(3.56 \mathrm{U} / \mathrm{mL})$ at $36 \mathrm{~h}$ in the hydrolysis process, followed by amylase (2.87
$\mathrm{U} / \mathrm{mL})$, endoglucanase $(0.98 \mathrm{U} / \mathrm{mL})$, xylanase $(0.87$ $\mathrm{U} / \mathrm{mL})$, and pectinase $(0.03 \mathrm{U} / \mathrm{mL})$. After inoculation with L. mesenteroides, xylanase $(2.01 \mathrm{U} / \mathrm{mL})$ activity increased until the fourth day (data not shown). Banana peel and corncob are potential carbon sources for the production of $\beta$-glucosidase, amylase, endoglucanase and xylanase from A. awamori NBRC 4388.

Some previous productions of D-lactic acid from biomass have been reported. L. plantarum NCIMB 8826 produced $102.3 \mathrm{~g} / \mathrm{L}$ of D-lactic acid from pulverized hardwood pulp by simultaneous saccharification and fermentation (Hama et al. 2015). L. delbrueckii LD 0025 and LD 0028 produced $62.6 \mathrm{~g} / \mathrm{L}$ of D-lactic acid from $10 \%$ rice saccharificate (Chang et al. 1999). Finally, Escherichia coli W3110 produced $48.7 \mathrm{~g} / \mathrm{L}$ of D-lactic acid with $5.4 \%$ molasses as the substrate (Shukla et al. 2004). Even though the D-lactic acid production from banana peel $(31.8 \mathrm{~g} / \mathrm{L}$ of D-lactic acid) and corncob (38.3 g/L of D-lactic acid) obtained in this study was not as high as that obtained from other carbon sources, our study indicated the high potential of these unutilized biomasses for D-lactic acid production in combination with $L$. mesenteroides and A. awamori. 
L. mesenteroides is a heterofermentative microorganism that produces not only D-lactic acid, but also ethanol and acetic acid. In this study, in MPF using banana peel, $0.223 \mathrm{~g} / \mathrm{L}$ of ethanol and $2.18 \mathrm{~g} / \mathrm{L}$ of acetic acid were produced, respectively. In fermentation using corncob, $0.562 \mathrm{~g} / \mathrm{L}$ of ethanol and $1.78 \mathrm{~g} / \mathrm{L}$ of acetic acid were produced, respectively. These results showed that ethanol production using banana peel was a little lower than that using corncob and that acetic acid production using banana peel was a little higher than that using corncob.

\section{Conclusion}

The Taguchi method using an L8 orthogonal array enabled us to analyze the influence of several factors and their interactions on D-lactic acid production using banana peel and corncob biomass substrates. Our data revealed that optimal D-lactic acid production using MPF from banana peel and corncob biomass substrates $(31.8 \mathrm{~g} / \mathrm{L}$, productivity $0.331 \mathrm{~g} / \mathrm{L} / \mathrm{h}$, optical purity $99.99 \%$ and $38.3 \mathrm{~g} / \mathrm{L}$, productivity $0.159 \mathrm{~g} / \mathrm{L} / \mathrm{h}$, optical purity $99.98 \%$, respectively) was achieved using $15 \%$ carbon source (banana peel and corncob), $0.5 \% \quad \mathrm{KH}_{2} \mathrm{PO}_{4}, \quad 0.1 \%$ Tween $80,0.05 \%$ $\mathrm{MgSO}_{4} \cdot 7 \mathrm{H}_{2} \mathrm{O}, 0.05 \%$ (for banana peel) and $0.1 \%$ (for corncob) $\mathrm{NaCl}, 1.5 \%$ (for banana peel) and $1.0 \%$ (for corncob) yeast extract, and $0.2 \%$ (for banana peel) and $0.4 \%$ (for corncob) diammonium hydrogen citrate. This result indicated that utilization of such biomass substrates in MPF has a high potential for D-lactic acid production.

Acknowledgments We are grateful to Monbukagakusho, The Ministry of Education, Culture, Sports, Science and Technology in Japan (MEXT), for financial support (MEXT scholarship).

\section{Compliance of ethical standards}

Conflict of interest The authors declare that they have no conflict of interest in the publication.

Open Access This article is distributed under the terms of the Creative Commons Attribution 4.0 International License (http:// creativecommons.org/licenses/by/4.0/), which permits unrestricted use, distribution, and reproduction in any medium, provided you give appropriate credit to the original author(s) and the source, provide a link to the Creative Commons license, and indicate if changes were made.

\section{References}

Benninga H (ed) (1990) A history of lactic acid making. Kluwer Academic Publishing, Boston

Carminati D, Giraffa G, Quiberoni A, Binetti A, Suarez V, Reinhemer J (2010) Advances and trends in starter cultures for dairy fermentation chapter 10: biotechnology of lactic acid bacteria: novel applications. Edited by Mozi F, Raya RR, Vignolo GM. Wiley Blackwell Publisher
Chang DE, Jung HC, Rhee JS, Pan JG (1999) Homo fermentative production of D- or L-lactate in metabolically engineered Escherichia coli RR1. Appl Environ Microbiol 65:1384-1389

Coelho LF, de Lima CJ, Bernardo MP, Contiero J (2011) D-lactic acid production by Leuconostoc mesenteroides B512 using different carbon and nitrogen sources. Appl Biochem Biotechnol 164(7):1160-1171

Datta R, Tsai SP (1997) Lactic acid production and potential uses: a technology and economics assessment. ACS Symp Ser 666:224-236

Ghowdaman D, Ponnusami V (2015) Production and optimization of xylooligosaccharides from corncob by Bacillus aerophilus KGJ2 xylanase and its antioxidant potential. Int $\mathrm{J}$ Biol Macromol 79:595-600

Hama S, Mizuno S, Kihara M, Tanaka T, Ogino C, Noda H, Kondo A (2015) Production of D-lactic acid from hardwood pulp by mechanical milling followed by simultaneous saccharification and fermentation using metabolically engineered Lactobacillus plantarum. Bioresour Technol 187:167-172

Jeevan P, Nelson R, Rena E (2011) Optimization studies on acid hydrolysis of Corncob hemicellulosic hydrolysate for Microbial production of xylitol. J Microbiol Biotech Res 4:114-123

Lowry OH, Rosebrough NJ, Farr AL, Randall RJ (1951) Protein measurement with the folin phenol reagent. J Biol Chem 193:265-275

Lu H, Xiao Z, Yongze W, Xiaoren D, Jinhua W, Erin G, Ryan M, Andrew I, Shengde Z (2016) Enhancement of D-lactic acid production from a mixed glucose and xylose substrate by the Escherichia coli strain JH15 devoid of the glucose effect. BMC Biotechnol 16:19. doi:10.1186/s12896-016-0248-y

Luo J, Xia L, Lin J, Cen P (1997) Kinetics of simultaneous saccharification and lactic acid fermentation processes. Biotechnol Prog 13:762-767

Miura S, Arimura T, Itoda N, Dwiarti L, Feng JB, Bin CH, Okabe M (2004) Production of L-lactic acid from corncob. J Biosci Bioeng 97:153-157

Ravella SR, Ganesh KC, Shetty PR, Phil JH (2008) The Taguchi methodology as a statistical tool for biotechnological applications: a critical appraisal. Biotechnol J 3:510-523

Rehman S, Hina A, Aqeel A, Shakeel AK, Muhammad S (2014) Production of plant cell wall degrading enzymes by monoculture and co-culture of Aspergillus niger and Aspergillus terreus under SSF of banana peel. Brazil J Microbiol 45:1485-1492

Richard FG, Nwabunma D (2010) Poly (lactic acid) synthesis, structures, properties, processing, and application. Wiley Series on Polymer Engineering and Technology, series editors. A John Wiley \& Sons, Inc. Publication

Ruengruglikit C, Hang YD (2003) L (+)-lactic acid production from corncobs by Rhizopus oryzae NRRL-395. Lebensm-Wiss. u.Technol 36:573-575

Sasaki C, Okumura R, Asakawa A, Asada C, Nakamura Y (2012) Production of D-lactic acid from sugarcane bagasse using steamexplosion. J Phys Conf Series 352(1)

Shukla VB, Zhou S, Yomano LP, Shanmugam KT, Preston JF, Ingram LO (2004) Production of D-lactate from sucrose and molasses. Biotechnol Environ Lett 26:689-693

Somogyi M (1952) Notes on sugar determination. J Biol Chem 195:19-23

Tanaka T, Hoshina M, Tanabe S, Sakai K, Ohtsubo S, Taniguchi M (2005) Production of D-lactic acid from defatted rice bran by simultaneous saccharification and fermentation. Bioresour Technol 97:211-217

Wang YT, Xiang YF, Sang ML, Jie Y, Jian WL, Dong ZW, Yoon MK (2003) Purification of $\mathrm{L}(+)$-lactic acid from fermentation broth with paper sludge as a cellulosic feedstock using weak anion exchanger Amberlite IRA-92. Biochem Eng J 18:89-96

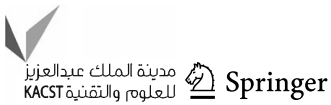


Wang Q, Zhao X, Chamu J, Shanmugam KT (2011) Isolation, characterization and evolution of a new thermophilic Bacillus licheniformis for lactic acid production in mineral salts medium. Bioresour Technol 102:8152-8158
Zhou Y, Domínguez JM, Cao N, Du J, Tsao GT (1999) Optimization of L-lactic acid production from glucose by Rhizopus oryzae ATCC 52311. Appl Biochem Biotechnol Spring 77-79:401-7 